\title{
Avaliação mecânica, morfológica e físico-química, de couros de corvina, pescada amarela e tilápia
}

\author{
Mechanical, morphological and physical-chemical evaluation of corvina, pescada amarela and \\ tilapia leathers \\ Evaluación mecánica, morfológica y fisicoquímica de cueros de corvina, pescada amarela y tilápia
}

Recebido: 01/11/2021 | Revisado: 09/11/2021 | Aceito: 13/11/2021 | Publicado: 23/11/2021

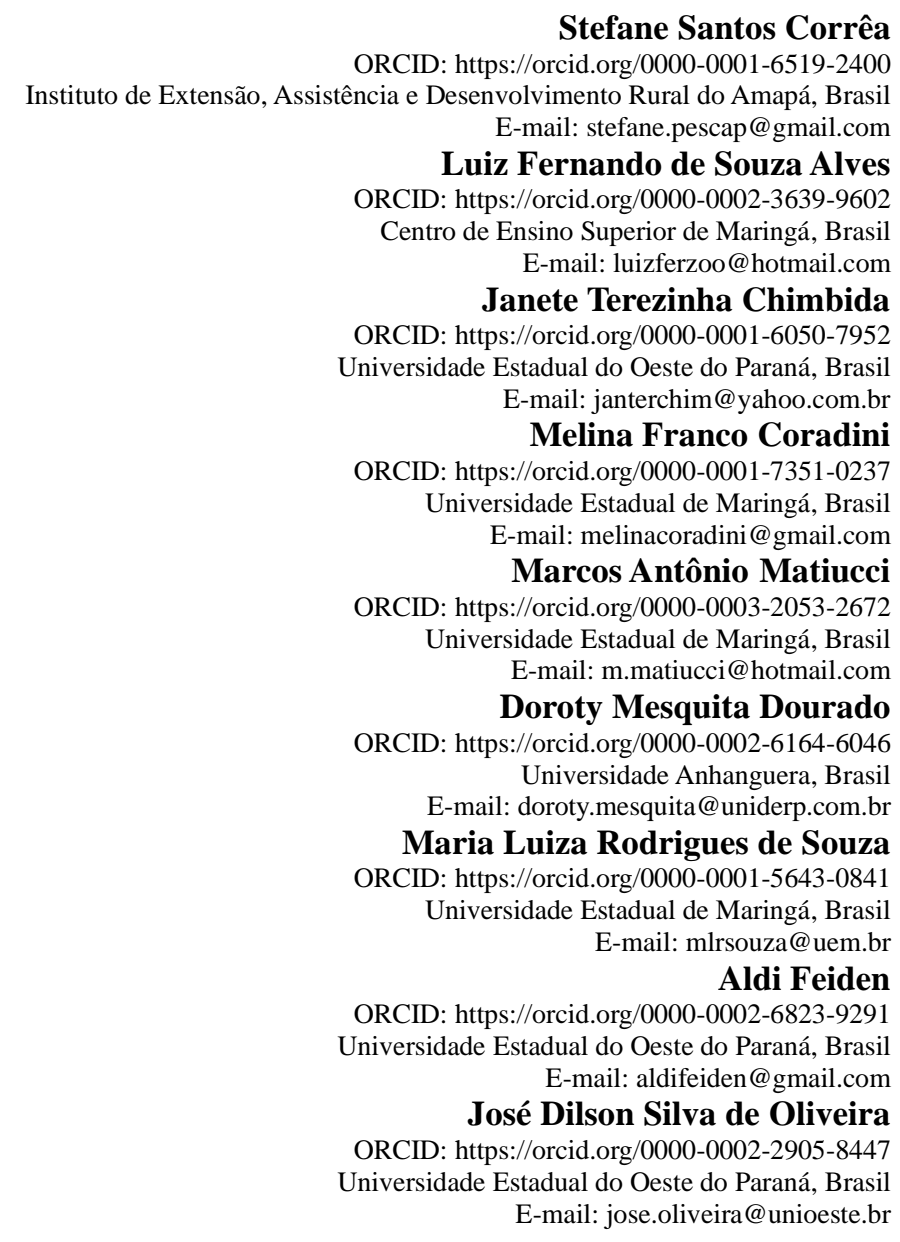

\section{Resumo}

O objetivo do estudo foi avaliar os couros de corvina e pescada amarela e de tilápia. As peles foram submetidas ao processo de curtimento com tanino vegetal e foram avaliadas pelos testes de resistência à tração e alongamento, rasgamento progressivo nos corpos de prova dos couros, além da análise morfológica e físico-química, visando averiguar a eficiência do processo e observar o comportamento da estrutura das fibras colágenas após o tratamento. Dentre as amostras, o couro de tilápia apresentou menor resistência mecânica, isto em função da arquitetura histológica, pois apresenta maior percentual de fibras finas em relação às espessas. $\mathrm{O}$ couro de pescada amarela apresentou mais resistência à tração $\left(21,64 \mathrm{~N} / \mathrm{mm}^{2}\right.$ na transversal), maior elasticidade no sentido transversal $(105,60 \%)$ e maior resistência ao rasgamento no sentido transversal $(98,1 \mathrm{~N} / \mathrm{mm})$ e, o couro de corvina necessitou de menor força no sentido transversal $(59,83 \mathrm{~N})$ comparado ao longitudinal $(86,50 \mathrm{~N})$ mesmo apresentando menor espessura. Constatou-se, para as amostras de couros das espécies estudadas uma baixa quantidade de óleo no engraxe observado pela análise de substâncias extraíveis em diclorometano, apesar de não ter interferido na resistência desses materiais analisados. Os resultados mostraram-se satisfatórios para os couros das três espécies de peixe, podendo ser aplicados para confecção de vestuário.

Palavras-chave: Resíduo pesqueiro; Curtimento; Cynoscion leiarchus; Cynoscion acoupa; Oreochromis niloticus. 


\begin{abstract}
The study aimed to evaluate the leathers of corvina and pescada amarela and tilapia. The hides were subjected to the tanning process with vegetable tannin and were evaluated by tensile strength and elongation tests, progressive tearing in the leather specimens, in addition to morphological and physical-chemical analysis, to ascertain the efficiency of the process and observe the behavior of the structure of collagen fibers after treatment. Among the samples, the tilapia leather showed lower mechanical strength, due to the histological architecture, as it presents a higher percentage of fine fibers about thick ones. The pescada amarela leather had more tensile strength $\left(21.64 \mathrm{~N} / \mathrm{mm}^{2}\right.$ in the transverse), greater elasticity in the transverse direction $(105.60 \%)$, and greater tear resistance in the transverse direction $(98.1$ $\mathrm{N} / \mathrm{mm})$ and, corvina leather required less force in the transverse direction $(59.83 \mathrm{~N})$ compared to the longitudinal $(86.50 \mathrm{~N})$ even with less thickness. For the leather samples of the studied species, a low amount of oil in the fatliquoring was observed, observed by the analysis of extractable substances in dichloromethane, despite not having interfered in the resistance of these analyzed materials. The results were satisfactory for the leathers of the three species of fish, which can be applied for making clothing.
\end{abstract}

Keywords: Fishery waste; Tanning; Cynoscion leiarchus; Cynoscion acoupa; Oreochromis niloticus.

\title{
Resumen
}

El objetivo del estudio fue evaluar las pieles de corvina y pescada amarela y tilapia. Los cueros fueron sometidos al proceso de curtido con tanino vegetal y fueron evaluados mediante ensayos de resistencia a la tracción y alargamiento, desgarro progresivo en las muestras de cuero, además de análisis morfológicos y físico-químicos, con el fin de conocer la eficiencia del proceso y observar la comportamiento de la estructura de las fibras de colágeno después del tratamiento. Entre las muestras, el cuero de tilapia presentó menor resistencia mecánica, esto debido a la arquitectura histológica, ya que presenta un mayor porcentaje de fibras finas en relación a las gruesas. El cuero de pescada amarela presentó mayor resistencia a la tracción $\left(21,64 \mathrm{~N} / \mathrm{mm}^{2}\right.$ en la transversal), mayor elasticidad en la dirección transversal (105,60\%) y mayor resistencia al desgarro en la dirección transversal $(98,1 \mathrm{~N} / \mathrm{mm})$ y, la corvina requirió menos fuerza en la dirección transversal $(59,83 \mathrm{~N})$ en comparación con la longitudinal (86,50 N) incluso con menor espesor. Para las muestras de cuero de las especies estudiadas, se observó una baja cantidad de aceite en el engrase, observado por el análisis de sustancias extraíbles en diclorometano, a pesar de no haber interferido en la resistencia de estos materiales analizados. Los resultados fueron satisfactorios para las pieles de las tres especies de peces, que se pueden aplicar para confección de ropa.

Palabras clave: Residuos de la pesca; Curtido; Cynoscion leiarchus; Cynoscion acoupa; Oreochromis niloticus.

\section{Introdução}

Embora a produção aquícola apresente crescimento ao longo dos anos, a pesca extrativista representa 53\% do pescado produzido em nível mundial (SOFIA, 2018) e, essa prática na região norte do Brasil representa uma atividade econômica de grande importância, sendo o estado do Amapá um dos estados que possuem uma grande representatividade.

Entre as espécies alvo da pesca extrativista no estado do Amapá estão a pescada amarela (Cynoscion acoupa) e a corvina (Cynoscion leiarchus), as quais ocorrem em abundância ao longo de toda a costa brasileira, enquanto a tilápia (Oreochromis niloticus) é a espécie de peixe mais produzida no Brasil, representando 60,6\% da produção de pescado (Peixe BR, 2021). Segundo Boscolo et al. (2001), tal fato se deve ao seu rápido crescimento, adaptação ao confinamento e aceitação da ração.

De acordo com Melo et al. (2011), a destinação de um terço do pescado capturado na região norte, segue para fabricação de ração ou é desperdiçado. Em meio a esse pescado encontram-se espécies de baixo valor comercial capturadas e sobras do processo do beneficiamento.

Diante desse cenário, a utilização de tecnologias para agregar valor à cadeia produtiva do pescado é uma forma de contribuir para o melhor aproveitamento e diminuição de impacto ambiental na região.

Segundo Boscolo e Feiden (2007), 65\% do peso total do peixe se tornam resíduos. Já Souza e Silva (2005) afirmam que $4,5 \%$ a $14 \%$ representam a pele do pescado, que varia dependendo da espécie e forma como é retirada, podendo representar maior quantidade de resíduos. De acordo com Prado et al. (2014), os resíduos gerados no processo de beneficiamento são considerados um problema para os abatedouros, devido à dificuldade de escoamento desses resíduos da linha de produção. Estes, por sua vez, contribuem com o impacto ambiental da atividade. 
A pele de peixe, depois de beneficiada, é transformada em couro, tornando-se matéria prima de alta qualidade, peculiar e exótica, devido ao desenho formado pelas lamélulas de proteção e elos entre lamélulas que se formam na superfície do couro, conhecido como desenho flor. Diante dessa característica, o aproveitamento da pele para fabricação de couro pode representar fonte alternativa de renda.

A transformação da pele de peixe em couro trata-se de tecnologia bem difundida, pouco complexa e de fácil aplicação, para a qual se necessita de mais conhecimentos, pois cada espécie de peixe possui suas características próprias e, diante da diversidade de espécies, há necessidade de adequação das técnicas de curtimento, visando o melhor aproveitamento para produção de couro de boa qualidade.

O curtimento com tanino vegetal é uma alternativa para minimizar os danos causados ao meio ambiente, tendo em vista que taninos são moléculas fenólicas biodegradáveis extraídas de cascas de árvores, principalmente da acácia negra, e suas características inibem o processo de putrefação de peles (Soleno, 1932).

Diante da realidade no estado do Amapá, a pescada amarela e a corvina foram escolhidas como objeto de análise desta pesquisa pela sua abundância, ocorrência, comprimento e por serem espécies alvo da pesca nessa região norte do Brasil. Já a tilápia do Nilo é cultivada em diferentes regiões do Brasil, onde o estado do Paraná se destaca pela maior produção, representando 21,4\% da produção nacional (Peixe BR, 2021), sendo utilizada neste estudo como objeto de comparação para os resultados das análises realizadas.

Com a preocupação de agregar valor a um resíduo que normalmente é descartado pelas indústrias da região norte do Brasil, o objetivo deste trabalho foi determinar a aplicabilidade da técnica de curtimento em peles de peixes oriundos da pesca extrativista dessa região, comparando-as ao final do processo à pele de peixe de uma espécie muito cultivada (tilápia do Nilo), com meio de contribuir para minimização do impacto de seu descarte no meio ambiente e reduzir o desperdício de matéria prima, por meio da viabilidade da comercialização do couro dessas espécies.

\section{Metodologia}

Esta pesquisa pode ser caracterizada como experimental (Pereira, et al., 2018). Foram utilizados para o estudo amostras de peles das espécies de peixes pescada amarela, corvina e tilápia. As amostras de peles das duas primeiras espécies de peixes foram cedidas por um frigorífico localizado na cidade de Calçoene, estado do Amapá, e as amostras de pele de tilápia obtidas junto a um frigorifico localizado na cidade de Toledo, estado do Paraná.

Foram utilizados $5 \mathrm{~kg}$ de peles inteiras de cada espécie, as quais, para mantê-las conservadas até o momento do curtimento, foram submetidas à salga seca imediatamente após o processo de descarne, sendo conservadas até o a execução do experimento. Posteriormente, as peles foram lavadas em água corrente, para a remoção do sal, e pesadas para cálculo da concentração dos reagentes a serem utilizados durante todo o processo de curtimento.

\section{Processamento dos couros}

Para o processamento dos couros, seguiu-se a metodologia de curtimento descrita por Maluf (2010) e Souza (2004) com adaptações. As peles de peixe foram submetidas às etapas de remolho, caleiro, desencalagem, purga, píquel, curtimento, neutralização, recurtimento, tingimento e engraxe. As peles foram curtidas em fulão (cilindro de madeira, com variação de rotação para a movimentação das peles em seu interior) com capacidade de 60 litros.

Para o tratamento, foram calculadas as quantidades de reagentes utilizados em porcentagem sobre o peso das peles amostradas. 
No remolho, as peles foram hidratadas com água e $0,5 \%$ de detergente por 1 hora. No caleiro, realizou-se a remoção do excesso de gordura, abertura da estrutura fibrosa e o intumescimento das fibras colágenas, utilizando- se para tanto $3 \%$ de cal, $2 \%$ de carbonato de cálcio, $0,5 \%$ de detergente, por 2 horas, e as peles pernoitaram em banho estático.

Para a etapa de desencalagem foi utilizada uma solução com sulfato de amônio e $0,5 \%$ de detergente (30 minutos). Ao término, as peles foram lavadas para a etapa de purga. Nesta foi adicionado 0,5\% de enzima proteolítica (Koropon $\mathrm{MK}^{\mathrm{R}}$ ) $\mathrm{e}$ $0,5 \%$ de detergente em $100 \%$ de água, por $20 \mathrm{~min}$. Decorrido esse período, foram adicionados $2 \%$ de neutralizante (sulfato de amônio) para inibir a ação da enzima, baixando o $\mathrm{pH}$ da solução, por um período de 20 minutos.

Para a etapa de píquel foram utilizados $6 \%$ de sal comum em $100 \%$ de água $\left(6^{\circ} \mathrm{Bi}\right)$ por 30 minutos, com a finalidade de proteger as fibras colágenas das peles no momento da adição do ácido, evitando-se a gelatinização e intumescimento ácido (Hoinacki, 1989). Após, foi adicionado 0,5\% de ácido fórmico, para baixar o pH e estabilizar em 4,0. As peles ficaram em repouso na solução de píquel por 48 horas. Na mesma solução píquel, decorrido esse período, foram adicionados $10 \%$ de tanino vegetal, divididos em duas vezes por 2 horas, descansando mais 28 horas. Esta etapa é considerada o curtimento propriamente dito, pois é neste momento que a pele é transformada em couro. Depois disso, adicionou-se $0,5 \%$ de bicarbonato de sódio diluído, dividido em três vezes (por 1 hora). Fez-se então a adição de 0,05\% de letarim MK (fungicida), por 15 minutos. Os couros foram submetidos a neutralização com $0,5 \%$ de bicarbonato de sódio em $100 \%$ de água (por 60 minutos), para atingir o $\mathrm{pH}$ de 5,5 e até 6,5.

O recurtimento e tingimento dos couros foram realizados com $2 \%$ de tanino vegetal e $2 \%$ de tanino sintético por 15 minutos. Em seguida, adicionou-se $1 \%$ de corante (30 minutos) e 0,5\% de ácido fórmico (dividido em três vezes, com intervalos de 15 em 15 minutos, por 2 horas).

Para finalizar, o engraxe foi realizado com $4 \%$ de óleo especial para couro em $30 \%$ de água aquecida, para formar a emulsão e adicionada ao fulão sob a temperatura de $45^{\circ} \mathrm{C}$. A finalidade desta etapa foi para proporcionar o deslizamento entre as fibras colágenas, evitando- se a sua aglutinação.

Os couros pernoitaram nessa etapa, depois foram lavados, colocados para secar em um varal e amaciados manualmente.

\section{Análise histológica dos couros}

Para realização da análise histológica, as amostras de couro foram retiradas da região dorsal dos peixes para análise histológica. As amostras foram incluídas em parafina e cortadas sob espessura de $5 \mu \mathrm{m}$ e coradas pela reação PicrosiriusHematoxilina (PH) e Hematoxilina/Eosina (HE). Após a aplicação, utilizou-se o programa IMAGELAB para auxiliar na captura de imagens. Foram preparadas 30 lâminas, analisadas por campo, num total de 2 campos por lâmina, para identificação e caraterização das fibras de colágeno, da camada dérmica dos couros.

\section{Testes de resistência dos couros}

Para o teste de resistência, foram utilizados 10 couros de cada espécie para a retirada dos corpos de provas, sendo o couro a unidade experimental. Dessa forma, foram retirados dois corpos de prova no sentido longitudinal, para tração e alongamento (ABNT, 2014) e 10 corpos de prova para rasgamento progressivo (ABNT, 2014). O mesmo procedimento foi realizado para retirada dos corpos de prova, no sentido transversal.

Os corpos de provas foram retirados com auxílio de balancim (ABNT, 2014) sendo determinadas as medidas em espessura (mm) dos corpos de provas (ABNT, 2014) para reduzir os diferentes testes de resistência (Figura 1).

Para cada corpo de prova foram observadas duas medidas de espessura para utilizar na análise de resistência (Figura 2), para o qual foi utilizado o dinamômetro da marca EMIC, e a velocidade de afastamento entre as garras foi de $100 \pm 20$ 
mm/N. Foi utilizada célula de carga de $200 \mathrm{~kg}$ para realização dos referidos testes. Foram determinadas também, no teste de resistência, a força máxima $(\mathrm{N})$ e a tração. A calibragem do aparelho foi realizada pela EMIC-DCARNE, laboratório credenciado pela CGERE/INMETRO, sob nº 197.

\section{Análises físico-químicas}

As análises físico-químicas foram realizadas no laboratório interno de uma indústria de couros localizadas na cidade de Apucarana, estado do Paraná. Onde, foram determinadas substâncias extraíveis em diclorometano (ABNT 2013), pH e cifra diferencial (ABNT 2006). Para esta análise foram utilizadas 2 amostras de couro de cada espécie, recortadas da parte referente à região dorsal dos peixes.

\section{Análises estatísticas}

Os resultados obtidos nas análises dos testes físico-mecânicos e quantificação de fibras colágenas foram submetidos à análise em fatorial $3 \times 2$, sendo três espécies de peixes (tilápia, corvina e pescada amarela) e dois sentidos (longitudinal e transversal). Os dados foram submetidos à análise de variância (ANOVA) e as médias foram comparadas realizando-se o teste de Tukey $(\mathrm{P}<0,05)$. Fez-se o uso do programa SAS Inst. Inc., Cary, NC, USA (2001) para auxiliar no ordenamento dos dados estatísticos.

\section{Resultados}

As peles, após submetidas ao processo de curtimento, apresentaram comprimento em média de 25,9 cm para o couro de tilápia, 60,7 cm para o couro da corvina e 64,9 cm para o couro da pescada, observando-se, portanto, o menor tamanho para os couros de tilápia, provenientes da aquicultura.

\section{Análises histológicas dos couros}

As peles das três espécies são formadas por três camadas distintas. As análises histológicas relatadas restringiram-se à camada dérmica de couro (Figura 1). 
Figura 1 - Desenho flor dos couros.
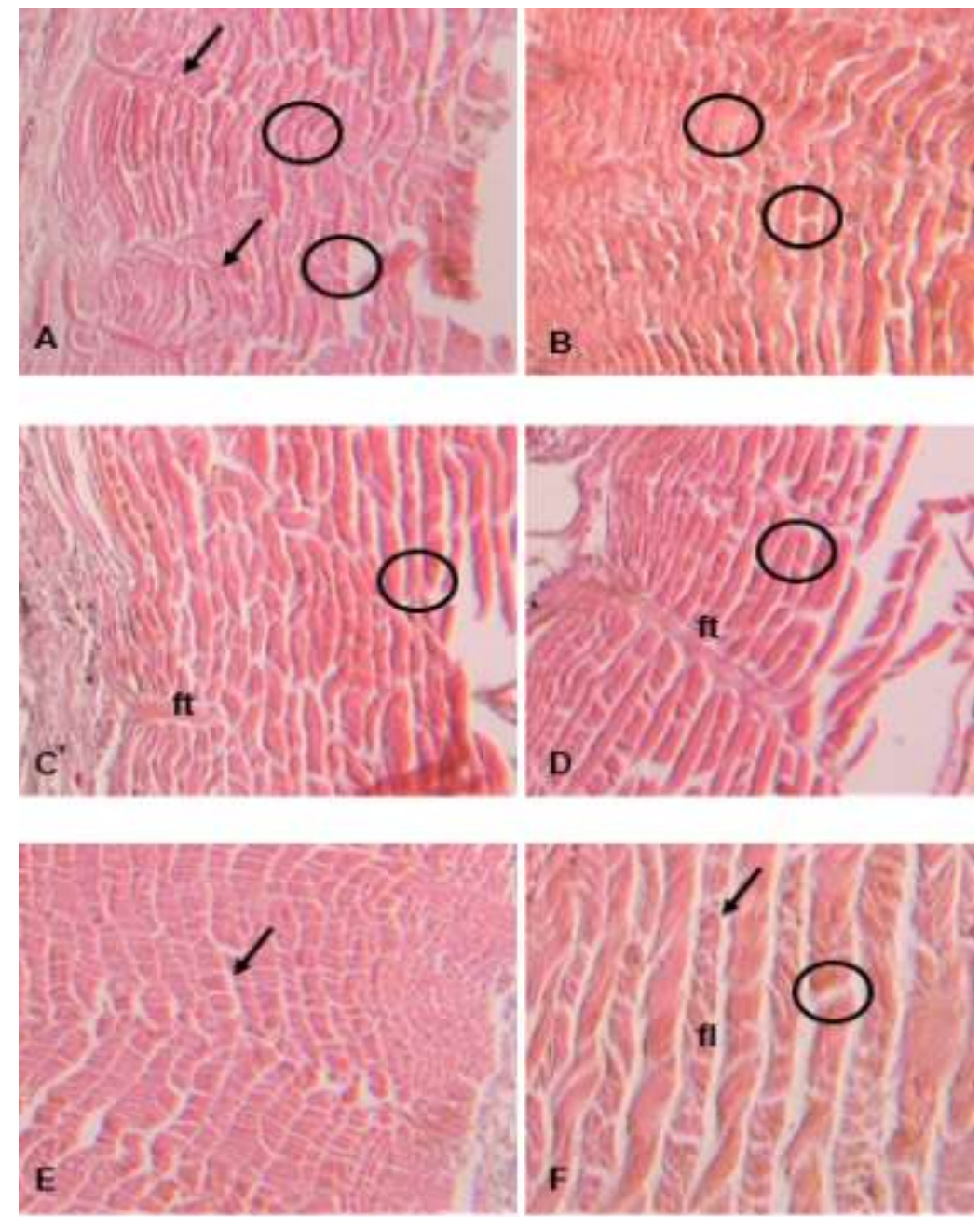

A-B - tilápia, C-D - corvina e E-F - pescada amarela, após o processo de curtimento ecológico. Coloração HE. Objetiva 40x. Fonte: Autores (2021).

A pescada amarela e a corvina apresentaram mais fibras finas no sentido transversal e mais fibras espessas no sentido longitudinal. Observando a média apresentada para o percentual dessas fibras, notou-se que estavam em equilíbrio ou havia menor variação entre elas, enquanto no couro de tilápia as fibras de colágenos finas se encontravam em maior proporção, tanto no sentido longitudinal $(78,20 \%)$ quanto no transversal $(79,65 \%)$. As fibras de colágenos espessas apresentavam-se em menores quantidades em ambos os sentidos (21,80\% na longitudinal e 20,34\% na transversal) do couro.

No couro de pescada amarela, as proporções das fibras de colágenos finas e espessas são diferentes, porém com pequena diferença entre elas (48,88\% finas e 51,13\% espessas). Observou-se o mesmo para a corvina (57,60\% finas e 42,48\% espessas). No couro de tilápia essa diferença foi elevada, para as fibras finas maior proporção $(78,93 \%)$ em relação às fibras de colágenos espessas $(21,80 \%)$. Esses dados estão apresentados na Tabela 1. 
Tabela 1 - Percentuais de fibras de colágeno finas e espessas nos sentidos longitudinais e transversais dos couros das três espécies de peixes.

\begin{tabular}{llcc}
\hline \multicolumn{1}{c}{ Couros } & \multicolumn{2}{c}{ Fibras colágenas $(\%)$} \\
\hline Tilápia & \multicolumn{1}{c}{ Sentido } & Finas & Espessas \\
& Longitudinal & $78,20 \pm 3,49^{\mathrm{a}}$ & $21,80 \pm 3,49^{\mathrm{b}}$ \\
Corvina & Transversal & $79,65 \pm 1,42^{\mathrm{a}}$ & $20,35 \pm 1,42^{\mathrm{b}}$ \\
& Longitudinal & $48,95 \pm 3,17^{\mathrm{b}}$ & $51,05 \pm 3,17^{\mathrm{a}}$ \\
& Transversal & $66,25 \pm 4,59^{\mathrm{a}}$ & $33,90 \pm 4,61^{\mathrm{b}}$ \\
Pescada amarela & Longitudinal & $42,65 \pm 2,96^{\mathrm{b}}$ & $57,35 \pm 2,96^{\mathrm{a}}$ \\
& Transversal & $55,10 \pm 7,35^{\mathrm{a}}$ & $44,90 \pm 7,35^{\mathrm{ab}}$ \\
\hline Efeitos principais & & & \\
\hline Espécies & Tilápia & $78,93 \pm 2,73$ & $21,03 \pm 2,73$ \\
& Corvina & $57,60 \pm 9,59$ & $42,48 \pm 9,52$ \\
& Pescada & $48,88 \pm 8,39$ & $51,13 \pm 8,39$ \\
\hline Sentido & Longitudinal & $56,60 \pm 15,94$ & $43,40 \pm 15,94$ \\
& Transversal & $67,00 \pm 11,28$ & $33,05 \pm 11,29$ \\
\hline Valor de p. & & & $<0,0001$ \\
\hline Espécie (E) & & $<0,0001$ & $<0,0001$ \\
Sentido (S) & & $<0,0001$ & $<0,0001$ \\
Interação (E x S) & & $<0,0001$ & 11,11 \\
\hline C.V.** $(\%)$ & & 6,87 & \\
\hline
\end{tabular}

*Médias na mesma coluna com letras distintas diferem significativamente pelo teste de Tukey $(\mathrm{p}<0,05) ; * *$ C.V.= Coeficiente de Variação. Fonte: Autores (2021).

Observou-se que a derme de tilápia apresentou camadas sobrepostas organizadas, sendo camadas de fibras mais finas próximas à superfície (região epidérmica) e se espessando à medida em que se apresentavam próximas da região da hipoderme (Figura 2 - A e B). Na derme havia um menor entrelaçamento entre as camadas de fibras longitudinais e transversais quando comparadas com as amostras de couro de corvina e pescada. 
Research, Society and Development, v. 10, n. 15, e163101522629, 2021

(CC BY 4.0) | ISSN 2525-3409 | DOI: http://dx.doi.org/10.33448/rsd-v10i15.22629

Figura 2 - Fotomicrografia da derme do couro dos peixes.
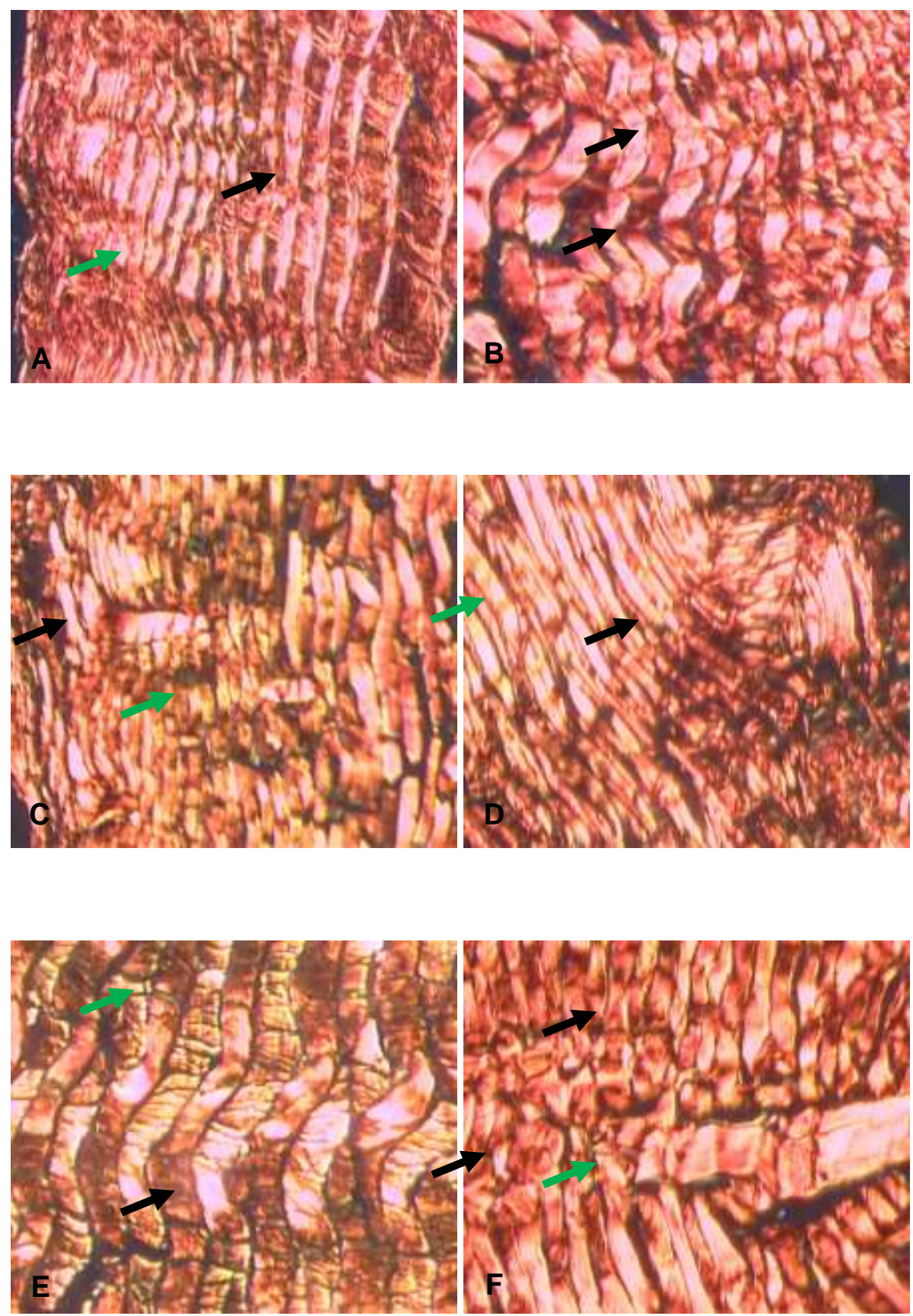

Tilápia (A e B), corvina (C e D) e pescada (E e F). No sentido longitudinal e transversal. Fibras espessas (vermelhas/ setas pretas): fibras finas (amarelas/ setas verdes). Coloração Picrosirius hematoxilina. Coloração Picrosirius hematoxilina. Objetiva 10x. Fonte: Autores (2021).

A derme da corvina, no sentido longitudinal, apresentava fibras colágenas espessas desorganizadas, interrompidas e, em alguns pontos, fibras colágenas espessas transversais curtas. No sentido transversal, apresentava fibras espessas que cortavam as fibras longitudinais (Figura 2 - C e D).

Para o couro de pescada amarela, observou-se no sentido longitudinal fibras colágenas espessas desorganizadas, septadas nos dois sentidos, e fibras espessas intercaladas com fibras espessas nos dois sentidos, o que caracteriza uma amarração entre as fibras, o que proporciona maior resistência ao couro (Figura 2 - E e F). 


\section{Testes de resistência dos couros}

Quando analisados os couros, com média obtida dos dois sentidos de retirada dos corpos de prova (longitudinal e transversal), para as três espécies de peixe, conforme a Tabela 2, observou-se que o couro de pescada amarela apresentou maior resistência à tração e significativa resistência para alongamento, ante o resultado para resistência ao alongamento oferecida pelo couro de corvina. Ainda, o couro de pescada amarela necessitou de maior força para realização desse teste, enquanto os couros de corvina e tilápia não apresentaram diferenças significativas para estes mesmos parâmetros avaliados.

No entanto, considerando o sentido de retirada dos corpos de prova de pescada amarela e corvina, os couros de pescada apresentaram maior resistência à tração e força máxima no sentido longitudinal. Contudo, para os couros destas mesmas espécies, o alongamento foi maior no sentido transversal.

Para o couro de tilápia constatou-se que o sentido transversal apresentou maior resistência à tração, mas, não apresentou diferença significativa para alongamento em ambos os sentidos. 
Tabela 2 - Valores médios de espessura, força máxima aplicada, tração e alongamento dos couros das espécies de peixes.

\begin{tabular}{|c|c|c|c|c|c|c|c|c|}
\hline & \multirow{2}{*}{\multicolumn{2}{|c|}{ Espessura (mm) }} & \multirow{2}{*}{\multicolumn{2}{|c|}{ Força $(\mathrm{N})$}} & \multirow{2}{*}{\multicolumn{2}{|c|}{ Tração $\left(\mathrm{N} / \mathrm{mm}^{2}\right)$}} & \multirow{2}{*}{\multicolumn{2}{|c|}{ Alongamento (\%) }} \\
\hline & & & & & & & & \\
\hline & Long. & Transv. & Long. & Transv. & Long. & Transv. & Long. & Transv. \\
\hline Tilápia & $1,36 \pm 0,23$ & $1,44 \pm 0,20$ & $151,77 \pm 42,10$ & $\begin{array}{c}191,40 \pm 104 \\
88\end{array}$ & $11,42 \pm 3,39 \mathrm{cB}$ & $17,84 \pm 6,04 \mathrm{bA}$ & $80,00 \pm 23,47 \mathrm{aA}$ & $70,22 \pm 13,66 \mathrm{cA}$ \\
\hline Corvina & $1,28 \pm 0,25$ & $0,79 \pm 0,26$ & $255,30 \pm 109,04$ & $\begin{array}{c}106,16 \pm 53,8 \\
0\end{array}$ & $22,36 \pm 5,70 \mathrm{bA}$ & $12,01 \pm 9,73 \mathrm{bB}$ & $49,77 \pm 7,15 \mathrm{cB}$ & $99,43 \pm 33,00 \mathrm{bA}$ \\
\hline Pescada & $2,14 \pm 0,61$ & $1,97 \pm 0,44$ & $537,33 \pm 244,31$ & $\begin{array}{c}422,30 \pm 60,8 \\
3\end{array}$ & $27,97 \pm 7,96 \mathrm{aA}$ & $21,64 \pm 2,62 \mathrm{aB}$ & $60,87 \pm 5,66 \mathrm{bB}$ & $105,60 \pm 14,93 \mathrm{aA}$ \\
\hline \multicolumn{9}{|l|}{ Valor de $\mathrm{P}$} \\
\hline Espécie & \multicolumn{2}{|c|}{$<0,0001$} & \multicolumn{2}{|c|}{$<0,0001$} & \multicolumn{2}{|c|}{$<0,0001$} & \multicolumn{2}{|c|}{$<0,0001$} \\
\hline Sentido do corte & \multicolumn{2}{|c|}{0,0426} & \multicolumn{2}{|c|}{0,0487} & \multicolumn{2}{|c|}{0,05} & \multicolumn{2}{|c|}{0,0001} \\
\hline $\begin{array}{c}\text { Interação } \\
\text { (espécie x } \\
\text { sentido) }\end{array}$ & \multicolumn{2}{|c|}{0,032} & \multicolumn{2}{|c|}{0,0649} & \multicolumn{2}{|c|}{0,0007} & \multicolumn{2}{|c|}{0,0001} \\
\hline $\mathrm{CV}(\%)$ & \multicolumn{2}{|c|}{20,74} & \multicolumn{2}{|c|}{43,34} & \multicolumn{2}{|c|}{23,56} & \multicolumn{2}{|c|}{23,46} \\
\hline
\end{tabular}

*Médias na mesma coluna com letras distintas diferem significativamente pelo teste de Tukey $(p<0,05) ; * *$ C.V.= Coeficiente de Variação. Legenda: Long. = Longitudinal; Transv. = Transversal. Fonte: Autores (2021). 
Também, considerando os dados da Tabela 3, observou-se que os couros de pescada amarela apresentaram maior espessura e, consequentemente, maior resistência ao rasgamento e maior força exercida para realizar o teste. Dessa forma, constatou-se interação apenas para força máxima $(\mathrm{N})$ e rasgamento.

Considerando a força máxima aplicada na determinação do rasgamento progressivo, os melhores resultados obtidos foram para a pescada amarela, em ambos os sentidos, longitudinal e transversal, não diferindo os dados entre si para esta espécie. Já o couro de tilápia apresentou a menor força quando avaliado o sentido longitudinal em relação aos demais couros, porém não havendo diferença entre os dados para a força aplicada no sentido transversal para essa mesma espécie.

O couro de corvina necessitou de menor força no sentido transversal comparado ao longitudinal, porém não diferindo do couro de tilápia no sentido transversal, observou-se que tal resultado não influenciou na determinação do rasgamento progressivo $(\mathrm{N} / \mathrm{mm})$ para o couro de corvina, embora apresentando menor espessura $(\mathrm{mm})$ na transversal.

Os couros de pescada amarela apresentaram maior resistência para todos os parâmetros avaliados. Isto está associado à disposição histológica das fibras de colágeno. Elas se intercalam de tal forma que as fibras são muito bem amarradas entre elas e, essas fibras são do tipo finas e espessas.

Tabela 3 - Valores médios obtidos no teste de determinação do rasgamento progressivo, interação entre espécies e sentido do corte.

\begin{tabular}{|c|c|c|c|c|c|c|}
\hline & \multicolumn{2}{|c|}{ Espessura (mm) } & \multicolumn{2}{|c|}{ Força Max $(\mathrm{N})$} & \multicolumn{2}{|c|}{ Rasgo (N/mm) } \\
\hline & Log. & Trans. & Long. & Trans. & Long. & Trans. \\
\hline Tilápia & $1,45 \pm 0,24$ & $1,36 \pm 0,14$ & $65,70 \pm 21,91 \mathrm{cA}$ & $74,90 \pm 19,02 \mathrm{bA}$ & $45,44 \pm 14,08$ & $55,67 \pm 16,19$ \\
\hline Corvina & $1,35 \pm 0,39$ & $0,85 \pm 0,31$ & $86,50 \pm 34,27 \mathrm{bA}$ & $59,83 \pm 21,83 \mathrm{bB}$ & $67,87 \pm 32,95$ & $72,05 \pm 17,20$ \\
\hline Pescada & $2,19 \pm 0,42$ & $2,10 \pm 0,40$ & $198,89 \pm 8,29 \mathrm{aA}$ & $200,10 \pm 4,04 \mathrm{aA}$ & $93,63 \pm 16,71$ & $98,11 \pm 17,08$ \\
\hline Média & $1,67 \pm 0,51 \mathrm{~A}$ & $1,53 \pm 0,58 \mathrm{~B}$ & $116,25 \pm 64,20 \mathrm{~A}$ & $119,57 \pm 66,93 \mathrm{~A}$ & $68,15 \pm 29,50 \mathrm{~A}$ & $75,77 \pm 24,96 \mathrm{~A}$ \\
\hline \multicolumn{7}{|l|}{ Valor de P } \\
\hline Espécie & \multicolumn{2}{|c|}{$<0,0001$} & \multicolumn{2}{|c|}{$<0,0001$} & \multicolumn{2}{|c|}{$<0,0001$} \\
\hline Posição & \multicolumn{2}{|c|}{0,0373} & \multicolumn{2}{|c|}{0,5878} & \multicolumn{2}{|c|}{0,2294} \\
\hline $\begin{array}{c}\text { Interação } \\
\text { (espessura x } \\
\text { posição) }\end{array}$ & \multicolumn{2}{|c|}{0,1559} & \multicolumn{2}{|c|}{0,0410} & \multicolumn{2}{|c|}{0,8705} \\
\hline $\mathrm{CV}(\%)$ & \multicolumn{2}{|c|}{20,80} & \multicolumn{2}{|c|}{17,00} & \multicolumn{2}{|c|}{27,29} \\
\hline
\end{tabular}

*Letras maiúsculas na mesma linha e letras minúsculas nas mesmas colunas diferem pelo teste de Tukey a 5\% de probabilidade;

**C.V.= coeficiente de variação. Legenda: Long. = Longitudinal; Trans. = Transversal. Fonte: Autores (2021).

\section{Análise físico-química}

Os resultados obtidos para análise físico-química estão descritos na Tabela 4. Para substâncias extraíveis em diclorometano, os resultados foram de 8,28\% para tilápia, 11,52\% para corvina e 7,37\% para pescada amarela. Já a determinação de pH para tilápia, corvina e pescada amarela fora de 4,99, 5,06 e 4,93 respectivamente. 
Tabela 4 - Valores da análise físico-química realizada nos couros.

\begin{tabular}{lccc}
\hline \multicolumn{1}{c}{ Espécie } & Tilápia & Corvina & Pescada Amarela \\
\hline Substâncias extraíveis em diclorometano & $8,28 \%$ & $11,52 \%$ & $7,37 \%$ \\
Determinação do $\mathrm{pH}$ & 4,99 & 5,06 & 4,96 \\
Determinação da Cifra Diferencial & $* * *$ & $* * *$ & $* * *$ \\
\hline
\end{tabular}

***A cifra diferencial somente age como um critério para a presença de ácidos fortes livres ou base em extrato aquoso com valores de $\mathrm{pH}$ abaixo de 4,0 ou acima de 10. Fonte: Autores (2021).

\section{Discussão}

O tamanho dos couros é uma característica particular para cada espécie, assim, como pode ocorrer uma variação em função do peso e abate dos indivíduos. $\mathrm{O}$ do couro pode ser considerado um fator atrativo para o mercado, assim como o desenho flor que se caracteriza pelo tamanho (abertura) e comprimento das lamélulas de proteção e inserção das escamas. Tais fatores podem despertar interesses por couros de peixes para confecção de vestuário.

A conjuntura das fibras de colágeno apresentada após o processo indica que as fibras de colágeno finas servem para amarrar melhor as fibras de colágenos espessas. A diferença é pequena em relação às fibras de colágenos finas e espessas dos couros de pescada amarela e corvina, quando avaliados os sentidos de corte do couro. Essas fibras proporcionam uma melhor amarração da estrutura histológica desses couros, gerando uma melhor resistência à tração, alongamento e rasgamento progressivo. Já, para os couros de tilápias a proporção de fibras colágenas finas é muito superior, quando comparadas com as fibras espessas, independente do sentido de análise do couro (longitudinal ou transversal) (Tabela 1). A grande diferença apresentada nessa arquitetura histológica é o que faz com que o couro de tilápia seja menos resistente aos testes de tração, alongamento e rasgamento progressivo, quando comparado aos couros das demais espécies (Tabela 2 e 3 ).

Pode-se inferir que o fato dos couros de pescada e corvina apresentarem maior elasticidade no sentido transversal pode estar associado à quantidade de fibras finas que estão em maior percentual nas suas peles (Tabela 1), proporcionando assim melhor amarração às fibras mais espessas. Também, pode-se considerar que devido às características das duas espécies de serem migradoras, necessitam de maior desenvolvimento para realização de movimentos migratórios mais longos.

Comparando os resultados de tração do couro de tilápia deste experimento com os de Yoshida et al. (2016), que trabalharam com a mesma espécie de peixe, nota-se que os couros foram menos resistentes a tração, assim como, no sentido de retirada do corpo de prova (Tabela 2). Os autores relatam que os couros de tilápia apresentaram maior tração no longitudinal $\left(22,17 \mathrm{~N} / \mathrm{mm}^{2}\right)$, valor esse muito superior ao deste experimento para o mesmo sentido $\left(11,42 \mathrm{~N} / \mathrm{mm}^{2}\right)$, enquanto no transversal $\left(17,19 \mathrm{~N} / \mathrm{mm}^{2}\right)$ o valor foi mais próximo ao relatado por Yoshida et al. (2016). Essa diferença relacionada ao maior valor de resistência e a diferença quanto ao sentido do couro analisado, poder ser justificada, devido ao agente curtente utilizado (Chomosal ${ }^{\circledR}$ ) e a técnica de curtimento aplicada que foi bem diferente das realizadas nesse experimento.

Eiras et al. (2015) fez uma adaptação no método de curtimento com tanino vegetal adaptado ao processo descrito por Souza (2004), para processar couros de pescada amarela e relataram que a tração foi de $44,56 \mathrm{~N} / \mathrm{mm}^{2}$, e a força máxima aplicada de 513,1 $\mathrm{N}$ e o alongamento de $62,53 \%$. O processo de curtimento foi de forma estática sem auxílio do fulão, com uma duração no processo de 18 dias. Estes valores foram superiores aos de tração $\left(24,81 \mathrm{~N} / \mathrm{mm}^{2}\right)$ e força máxima $(476,78 \mathrm{~N})$ obtidos neste experimento. Porém, a elasticidade (85,72\%) foi muito superior ao relatado por Eiras et al. (2015). Tudo indica que o tempo de processo também auxilia no aumento da resistência, devido ao maior tempo de exposição dos produtos, em especial de tanino, com as fibras colágenas proporcionando assim, uma maior reticulação no processo.

Os resultados de força na ruptura do couro de tilápia deste experimento foram próximos aos relatados por Hilbig et al. (2014). Os autores encontraram para a tilápia curtida em tanino vegetal, a força na ruptura de 112,47 N na longitudinal e 
$194,70 \mathrm{~N}$ na transversal, isto para couros de menor espessura $(0,88 \mathrm{~mm}$ a $0,99 \mathrm{~mm})$, quando comparados aos de tilápia deste experimento, que variou de 1,3 a $1,44 \mathrm{~mm}$.

Franco et al. (2011) e Franco et al. (2015) relataram que os arranjos das fibras colágenas são organizadas na longitudinal, transversal, proporcionando maior resistência ao couro curtido. Isto pode ser observado nestes couros analisados neste experimento, os quais possuem diferentes tipos de fibras colágenas finas e espessas que contribuem no arranjo da estrutura dérmica, diferenciando entre as três espécies.

Diante dessa conjuntura, o resultado mostra que é possível adaptar o processo de curtimento para cada espécie, separadamente, podendo então se alcançar melhores resultados de resistência e elasticidade.

Franco (2011) enfatiza que o agente curtente utilizado e o método empregado influenciam na qualidade aferida pelo teste de resistência, e que o cromo torna o couro mais macio, elástico e apresenta maior temperatura de retração do que outro curtente.

Dessa forma, segundo Franco et al. (2013), não há parâmetros específicos para se analisar os couros dos peixes, portanto, utilizam-se parâmetros definidos para couro bovino. De acordo com Hoinacki (1989) e BASF (2005), os valores para alongamento ou elasticidade devem estar acima de $60 \%$ para confecção de vestuário quando os couros forem curtidos com sais de cromo.

Para o couro bovino, Hoinacki (1989) afirma que a tração deve apresentar o valor mínimo de 9,80 N/mm². Para BASF (2005), a tração deve estar acima de $12 \mathrm{~N} / \mathrm{mm}^{2}$. Então, se considerando a média dos valores de tração apresentados (Figura 7), os couros da tilápia $\left(14,63 \mathrm{~N} / \mathrm{mm}^{2}\right)$, corvina $\left(17,19 \mathrm{~N} / \mathrm{mm}^{2}\right)$ e pescada amarela $\left(24,81 \mathrm{~N} / \mathrm{mm}^{2}\right)$ estão dentro dos resultados aceitáveis para confecção de vestuário.

Os resultados encontrados para o rasgamento progressivo no couro de tilápia foram superiores aos resultados encontrados por Godoy et al. (2010), que obtiveram o valor de 18,60 N/mm. Franco et al. (2015) encontraram até 20,16 N/mm para o couro de tilápia para determinação do rasgamento progressivo. Todavia, estes autores realizaram curtimento com sais de cromo, podendo este ter influenciado nos resultados.

Vieira et al. (2008) utilizaram o processo de curtimento de couro ecológico, com 6\% de tanino vegetal e $6 \%$ de tanino sintético, obtendo como resultado, 41,35 (N/mm) para rasgamento progressivo de couros de tilápia, concluindo que a técnica de curtimento empregada influencia na resistência dos couros.

Segundo BASF (2005), o valor mínimo exigido para o rasgamento progressivo é de $35 \mathrm{~N} / \mathrm{mm}$ para confecção de calçados e a espessura deve estar acima de 0,4 mm. Fazendo uma média entre os sentidos dos cortes, as três espécies estudadas apresentaram resultados superiores ao relatado pela BASF (2005), sendo 50,55 N/mm para tilápia, $69,96 \mathrm{~N} / \mathrm{mm}$ para corvina e 95,86 N/mm para pescada amarela (Figura 8).

O teste de substâncias extraíveis em diclorometano permite analisar a eficiência da etapa de engraxe e, segundo BASF (2005), o valor recomendado para este parâmetro deve estar entre $16 \%$ e $18 \%$, observando-se que os resultados obtidos para esse parâmetro para os couros analisados apresentaram-se com valores menores.

De acordo com os resultados na etapa de engraxe, não houve boa penetração e fixação do óleo adicionado aos couros e, tal resultado, mesmo apresentando baixos valores, não influenciou na resistência do couro, os quais se apresentaram ao final do processo atendendo ao padrão exigido para confecção de vestuário.

Considerando a etapa de engraxe, um aumento do percentual de óleo (acima de 4\%) permitiria a sua melhor permeação nos couros e, consequentemente, um resultado de teste de substâncias extraíveis em diclorometano mais elevado.

Já os valores de $\mathrm{pH}$ dos couros apresentaram pequena variação entre si, observando-se uma diferença máxima entre os couros das espécies estudadas de $0,11 \%$. Quanto ao óleo de engraxe, observou-se que não houve uma boa fixação. Isto ocorreu em função dos valores do pH dos diferentes couros, que deveriam apresentar-se em torno de 3,5 para melhor fixação 
dos óleos utilizados e, assim, a cifra diferencial apresentaria valores em consonância com o que preconiza BASF (2005). Contudo, valor de $\mathrm{pH}$ abaixo de 3,5 pode resultar em danos para a estrutura dos couros, tornando-os menos resistentes.

Assim, como na formulação aplicada para o tratamento dos couros não foi adicionado o ácido fórmico ao término do processo para a fixação dos óleos e, como os valores de pH dos couros apresentaram-se acima de 4,00, não foi possível observar a cifra diferencial para as amostras analisadas.

Ressalta-se que a quantidade de óleo utilizado no curtimento descrito por Maluf (2010), a 4\%, é um percentual baixo se comparado com as metodologias de Hoinacki (1989) e Souza (2004), que indicam quantidades acima de $8 \%$ de óleos no engraxe. Prado (2014) utilizou $10 \%$ de óleo no engraxe para o curtimento com tanino vegetal e, em seus resultados, não encontrou diferença significativa entre o teste de resistência da espécie surubim submetido ao curtimento com tanino e com sais de cromo.

\section{Conclusão}

Neste estudo foi possível observar que cada espécie tem características particulares quanto à arquitetura histológica das fibras de colágeno na derme, e isso pode ter influência no resultado final do curtimento de couros. Os testes de resistência à tração e alongamento e rasgamento progressivo mostraram que o couro de pescada amarela apresentou melhores resultados, o que pode estar relacionado com a espessura, mas, principalmente, devido à distribuição das fibras de colágeno finas e espessas. A análise físico-química dos couros permitiu verificar que é preciso adequar a etapa de fixação do engraxe no processo de curtimento ecológico, para que os couros destas espécies estudadas alcancem melhores resultados.

Com isso, novos estudos são importantes para avaliar o couro de outras espécies de peixes, reduzindo o desperdício de matéria prima e agregando valor a novos produtos no mercado.

\section{Referências}

ABNT - Associação brasileira de normas técnicas. (2013). NBR 11030: Couro - determinação de substâncias extraíveis em diclorometano. 1-4.

ABNT - Associação brasileira de normas técnicas. (2015). NBRISO 2418: Couro - Ensaios químicos, físicos e mecânicos e de solidez - Local da amostragem. $1-7$.

ABNT - Associação brasileira de normas técnicas. (2014). NBR ISO 3376: Couro - determinação da resistência a tração e ao alongamento. 1-5.

ABNT - Associação brasileira de normas técnicas. (2016). NBR ISO 2589: Couro - Ensaios físicos e mecânicos - Determinação da espessura. 1-2.

ABNT - Associação brasileira de normas técnicas. (2014). NBR ISO 3377: Couro - Ensaios físicos e mecânicos - Determinação da força de rasgamento - Parte 1: Rasgamento de extremidade simples. 1-4.

ABNT - Associação brasileira de normas técnicas. (2006). NBR 11057: Couro - determinação do pH e da cifra diferencial. 1-3.

BASF. (2005). Vademécum do curtidor. Ludwighafen. 455p.

Boscolo, W. R. \& Feiden, A. (2007). Industrialização de Tilápias. Toledo: GFM Gráfica e Editora. 272p.

Boscolo, W. R., Hayashi, C., Soares, C. M., Furuya, W. M., Meurer, R. F. (2001). Desempenho e característica de carcaça de macho revestido de tilápia do Nilo (Oreochromis niloticus), linhagem tailandesa e comum, nas fases iniciais e de crescimento. Revista Brasileira de Zootecnia, 30(5), 1391-1396.

Eiras, B. J. C. F., Medeiros Junior, E. F., Alves, M. M. (2015). Development of an artisanal tanning method of the acoupa weakfish (Cysnoscion acouoa) skin and its transfer through a workshop to a community in the city of Bragança, PA, Brazil. Semina: Ciências Agrárias, 36(2), 1123-1134.

Hilbig, C. C., Fockink, D. H., Maluf, M. L. F., Boscolo, W. R., Feiden, A. (2014). Resistência do couro de tilápia e composição centesimal da pele nas operações de ribeira e curtimento. Scientia Agraria Paranaenses, 12(4), 258-266.

Hoinacki, E. (1989). Peles e couros: origens, defeitos, industrialização. (2a ed.), 319p.

Franco, M. L. R. S. (2011). Transformação da pele do peixe em couro. Tecnologia do pescado: ciência, tecnologia, inovação e legislação. Atheneu. 4, 407-425.

Franco, M. L. R. S., Uchimura, C. M., Prado, M., Yajima, E. M., Gasparino, E., Silva, S. C. C. (2013). Qualidade da pele do salmão, salmo solaris: teste de resistência e hidroxiprolina. Arquivo Ciência do Mar, 46(1), 90-95. 
Research, Society and Development, v. 10, n. 15, e163101522629, 2021 (CC BY 4.0) | ISSN 2525-3409 | DOI: http://dx.doi.org/10.33448/rsd-v10i15.22629

Franco, M. L. R. S., Viegas, E. M. M., Kronka, S. N., Gasparino, E., Pontara, L. P., Del Vesco, A. P. (2015). Qualidade de resistência do couro de tilápia do Nilo em função da técnica de curtimento. Acta Tecnológica, 10(1), 24-31.

Godoy, L. C., Gasparino, E., Franco, M. L. R. S., Franco, N. P., Dourado, D. M. (2010). Teste físico-mecânico e físico-químico do couro da tilápia vermelha. Arquivo Brasileiro de Medicina Veterinária e Zootecnia, 62(2), 475-480.

Maluf, M. L. F. (2010). Curtimento ecológico de pele de peixe. Toledo, 42p.

Melo, F. O., Alves, M. M., Guimarães, M. D. F., Holanda, F. C. A. F. (2011). Aproveitamento de resíduo a partir do beneficiamento de pescado de uma indústria pesqueira no norte do Brasil. Arquivos Ciência do Mar, 44(3), 3-11.

Peixe BR - Associação Brasileira da Piscicultura. (2021). Anuário Peixe BR da Piscicultura. Texto Comunicação Coorporativa. 71p.

Prado, M., Franco, M. L. R. S., Bielawski, K., Souza, E. D., Gasparino, E., Silva, S. C. C., Del Vesco, A. P. (2014). Características de resistência dos couros de pseudoplatystoma sp. submetidos a alterações do processo de curtimento. Revista Cientifica de Produção Animal. 16(1), 46-59.

Souza, M. L. (2004). Tecnologia para processamento de pele de peixes. Eduem. 59p.

Souza, M. L. R. \& Silva, L. O. (2005). Efeito de técnicas de recurtimento sobre a resistência do couro da tilápia do Nilo (Oreochromis niloticus). Acta Scintiarum Animal Sciencrd, 27(4),.535-540.

Vieira, A. M., Kachba, Y. R., Franco, M. L. R. S., Oliveira, K. F., Godoy, L. C., Gasparino, E. (2008). Curtimento de peles de peixe com taninos vegetal e sintético. Acta Scientiarum Animal Science, 30(3), 359-363.

Yoshida, A, G, M., Kunita, N. M., Souza, M. L. R., Gasparino, E. (2016). Análise mecânica e físico-química de couros de tilápia, cachara e salmão. Archivos Zootecnia, 65(251), 349-355. 